\title{
Pharmacy education in India and its neighbouring countries
}

\author{
*Ayushy Sachan ${ }^{1}$, Anupam K Sachan1, Sudhir S Gangwar² \\ 1Dayanand Dinanath College, Institute of Pharmacy, Kanpur, Uttar Pradesh, India 209214 \\ ${ }^{2}$ Department of Pharmacy, G.S.V.M. Govt. Medical College, Kanpur, Uttar Pradesh, India 208001
}

\begin{abstract}
During the past few years, the pharmacy profession has expanded significantly in terms of professional services delivery and now has been recognized as an important profession in the multidisciplinary provision of health care. The Pharmacist is a key component of healthcare and manages the human resource to support the growth. In contrast to the situation in developed countries, pharmacists in developing countries are still underutilized and their role as health care professionals is not deemed important by either the community or other health care providers. The aim of this paper is to highlight the role of pharmacists in developing countries, particularly in India, Pakistan and Bangladesh. The paper draws on the literature related to the pharmacy profession in the country in the context of the current directions of health care. The paper highlights the current scenario and portrays the pharmacy profession in India, Bangladesh and Pakistan. It concludes that although the pharmacy profession in developing countries is continuously evolving, the health care system which yet to recognize the pharmacist's role. This lack of recognition is due to the limited interaction of pharmacists with the public. Pharmacists in developing countries are concerned about their present professional role in the health care system. The information presented in this paper may stimulate discussion and critical analysis and planning, and will be of value in further adaptation of the pharmacy education to desired educational outcomes. These are times of enormous change in healthcare and the pharmacy profession and pharmaceutical education must prepare students to enter into the practice of pharmacy.
\end{abstract}

Key Words: Pharmacy profession, developing countries, pharmacists.

\section{INTRODUCTION}

The World Health Organization (WHO) has defined health as the state of complete physical, mental and social well-being and not merely the absence of disease or infirmity. Within the context of this definition, health care providers play a major role in striving for health in a population. In terms of modern health care delivery, studies have shown that engaging multidisciplinary expertise is one of the goals for achieving ultimate population health. Although the pharmacy profession is recognized for its importance as a health care provider in many developed countries, in most developing countries it is still underutilized (Jesson et al., 2006).

\footnotetext{
*Corresponding Author:

Ayushy Sachan

Dayanand Dinanath College

Institute of Pharmacy

Kanpur, Uttar Pradesh, India-209214.

E-mail: ayushy.sachan@gmail.com

Contact No.: +917275329722
}

\section{The Pharmacist as a health care provider}

Pharmacy is the health profession that links the health sciences with the basic sciences; it is committed to ensuring the safe and effective use of medication .Pharmacists' professional roles and responsibilities have evolved historically from a focus on medication compounding and dispensing to extended pharmaceutical care services.

An increase in health demands, with a complex range of chronic medicines and poor adherence to prescribed medicines, has forced pharmacists to take a patient-centered approach.The paradigm shift for pharmacy practice took turn in 1990, when Hepler and Strand introduced the term "pharmaceutical care". Over the last few decades, pharmacy organizations and academic training programmes around the world have promoted pharmaceutical care as a philosophy and standard of provision of care for patients. In essence, the pharmaceutical care concept has transformed the pharmacy profession to be more accountable in patient care, especially to 
ensure that a patient achieves positive outcomes from drug therapy (Jesson et al., 2006).

In many parts of the world, pharmacists have played a significant role in provision of pharmaceutical care services. In addition, it is also widely believed that pharmacists can make a great contribution to the provision of the primary health care, especially in developing countries. Their role varies in different parts of the world: some deal with the preparation and supply of medicines, while some focus on sharing pharmaceutical expertise with doctors, nurses and patients.

\section{The pharmacy profession in the international context}

WHO has contributed effectively towards encouraging and defending the role of pharmacists worldwide. Although all health care providers and the public are rationally involved in using drugs, WHO has recommended a special role for pharmacists, particularly in quality assurance and the safe and effective administration of drugs (Singh, 2009). The International Pharmaceutical Federation (FIP) and WHO developed the concept of "The seven star pharmacist", which stated that a well-rounded pharmacist should be a compassionate care giver, decision maker, active communicator, lifelong learner and good manager; and should possess good leadership qualities and the ability to be a teacher and researcher. According to $\mathrm{WHO}$, future pharmacists must possess specific knowledge, attitudes, skills and behaviors in support of their roles. Besides their pivotal role in public health, pharmacists can also act as advisors to physicians and nurses and contribute to policy decisions (Singh, 2009).

\section{Pharmacy practice in developing countries}

Pharmacy practice models in developing countries vary significantly from one country to another. Some of the major issues identified as barriers to effective pharmacy practice models in these countries include an acute shortage of qualified pharmacists and no implementation of dispensing separation practices - especially in countries where the pharmacist is not the sole dispenser and medical practitioners are allowed to dispense as well - and a lack of standard practice guidelines (Hepler et al., 1990).
For example, in a country such as Malaysia, which is one of the leading countries in terms of economic growth in the south-east Asia region, there is an acute shortage of pharmacists practicing in community settings .Data for 2006 showed that the ratio of pharmacists to population in Malaysia was 1:6207.

Doctors in Malaysia still dispense medications as a part of their professional practice. There is still no separation of functions related to drug dispensing and prescribing between doctors' clinics and pharmacies. Registered pharmacists are not the only professionals with the legal right and responsibility of dispensing medications. Although the call for separation has been made for the last 20 years, the government still believes that due to the shortage of pharmacists the separation cannot be implemented. Another reason for delaying the separation is the objection of medical practitioners.

Looking at the perspective of African nations such as Ghana, the shortage of pharmacists is even worse: it has been reported that only 619 pharmacists are serving 2.9 million people in Greater Accra, which is far behind the WHO recommendation (Hepler et al., 1990). In developing countries, the urban population is more affluent. As a result, health professionals such as pharmacists prefer to work in cities rather than rural areas. The lack of human resources creates a significant difference between the health services available in the urban and rural areas. In many cases this is due to the shortage of pharmacists.

Other countries, such as India, have a comparatively high number of trained pharmacists, but their pharmacy training is focused more towards the industrial sector. This is due mainly to the demand from the industrial side and the focus of the national pharmacy curriculum in most universities, which covers mainly subjects pertaining to the production aspects of pharmaceuticals.

Pharmaceutical services in developing countries face some specific challenges unlike those faced by pharmacists in the developed world. In most developing countries, lack of appropriate and goodquality medicines is the most common problem encountered .Irrational use of medicine and weak regulatory enforcement of drug sales are also 
serious issues in developing countries. For example, findings from a survey conducted in a rural region of Ghana revealed that drug retailers in five pharmacy shops were found to have little or no training in pharmacy; the population bought drugs without prescriptions; the staff of these shops contributed to drug misuse by providing misinformation about drugs and selling drugs according to popular demand (Hepler et al., 1990).

\section{PHARMACY EDUCATION IN INDIA}

The earliest traditional systems of medicine practiced in India have been Ayurveda and Siddha. The Unani Greco- Arabic medical system came from West Asia. The colonial period brought the new western system of medicine and paved the way to emerge pharmacy houses in India. Though pharmacy was practiced since ages in India, it is recognized as a profession from 18th century only (Miglani, 2008).

The origin of pharmacy institutions in India dates back to 1899 in Madras for training of pharmacists followed by the state medical faculty of Bengal in 1928. Prof. M.L. Schroff, father of pharmacy education in India, started UG program in pharmacy at BHU in the year 1932, later, Andhra University in 1937, Madras University in 1938, Bombay University in 1943, Punjab University in 1944 and L.M. College in 1947 started degree programme. The statutory regulation of pharmacy institutions in India was established with the enactment of the Pharmacy Act 1948, and The Pharmacy Council of India was established in the year 1949 and the first education regulations (ER) framed in 1953, which were subsequently amended in 1972, 1981 and 1991 (Miglani, 2008). The PCI regulates the pharmacy education and profession in India At present there are more than 1500 institutions offering various pharmacy programmes of Diploma, UG, PG and Pharm.D with an annual intake of more than $1,00,000$ students. The syllabus is more industry oriented and mainly focused to cater the needs of the Pharmaceutical Industry. The Pharmacists with UG and PG qualification preferred working in Industry rather than Community Pharmacy due to lucrative job opportunities and most of the community pharmacists engaged are Diploma holders in India. The patent regime triggered the growth of Indian Pharma Industry as innovative Industry. The availability of vast technical pool, skilled manpower, well-established state of art manufacturing plants, made Indian Pharma Industry as global Pharma destination.

The Pharmacy Council of India (PCI), The Indian Pharmaceutical Association (IPA) and leaders of pharmacy profession have undertaken several initiatives including the rolling out of the Charter of Pharma Vision 2020, released by His Excellency Dr. A.P.J. Abdul Kalam, during 55th IPC 2003 at Chennai and roadmap document during 58th IPC 2006 at Mumbai proposing various activities to shape the future of pharmacy profession and pharmaceutical services in India by 2020 (Lal et al., 2005).

The changing scenario in societal requirement and more emphasis on health care system indicates clear shift in the science based pharmacy education to practice based. With successful implementation of PG programmes in Hospital Pharmacy and Pharmacy Practice in selected institutions, the Policy makers and Pharmacy educators in India proposed the introduction of Pharm.D programme (5 yrs of training and $1 \mathrm{yr}$ internship). As a major breakthrough in the history of Pharmacy education in India, The Pharm.D regulations $\mathrm{u} / \mathrm{s} 10$ of the Pharmacy Act 1948, have been notified in the Gazette of India on10thMay, 2008 with an aim to equip the future pharmacist of India with skills of not only dispensing medicines but also to serve as counselor of medicines with focus towards patients and prescriber of drugs (Lal et al., 2005).

\section{Educational Programmes}

A variety of pharmacy degree programs are offered in India: diploma in pharmacy (DPharm), bachelor of pharmacy (BPharm), master of pharmacy (MPharm), master of science in pharmacy [MS(Pharm)] and master of technology in pharmacy [MTech (Pharm)], doctor of pharmacy (PharmD), and doctor of philosophy in pharmacy (PhD). The entry point, for DPharm, BPharm, and PharmD programs is 12 years of formal education in the sciences. The DPharm program requires a minimum of 2 years of didactic coursework followed by 500 hours of required practical training anticipated to be completed within 3 months in either a hospital or community setting (Kaul, 2009). The BPharm involves 4 years of study in colleges affiliated with 


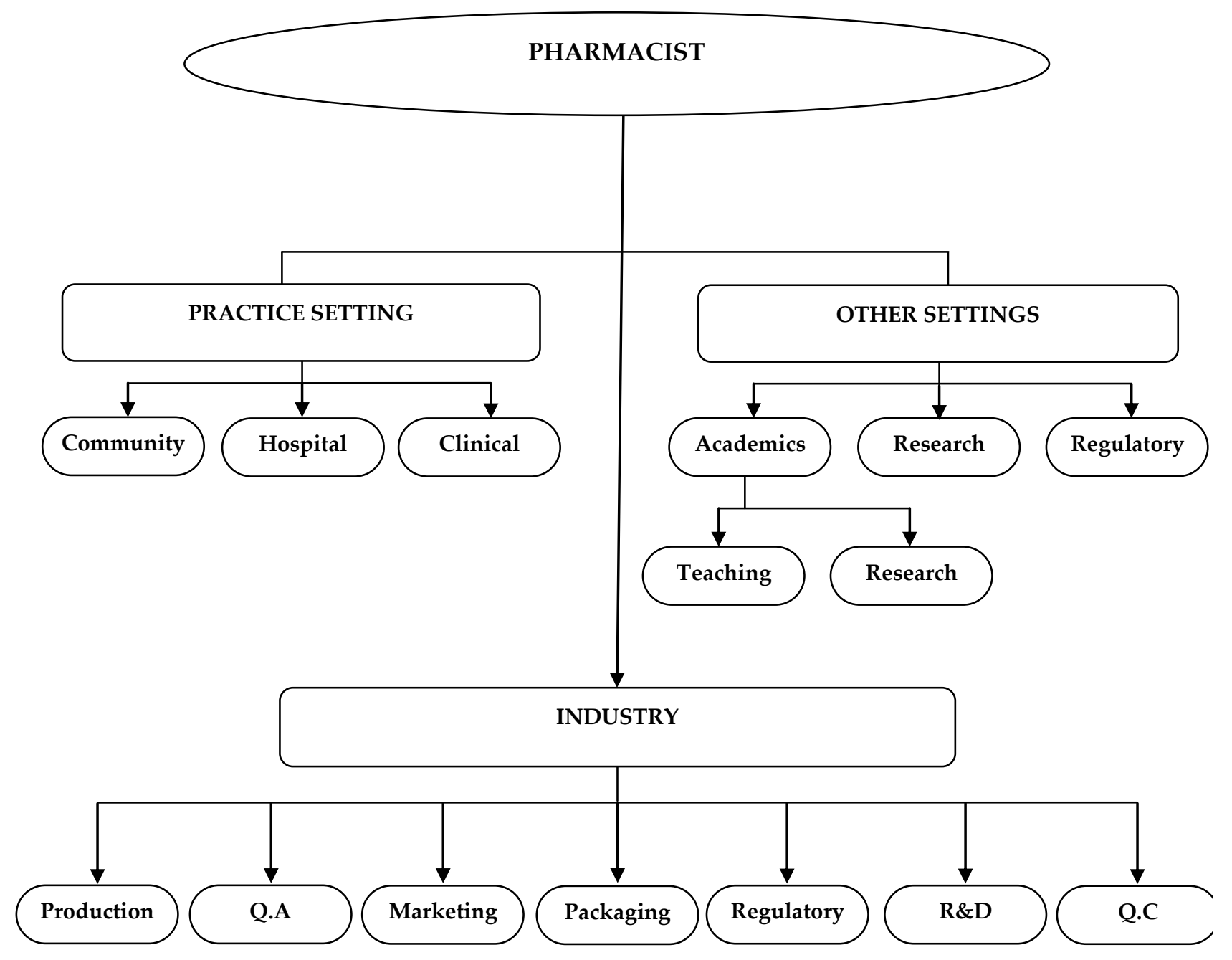

Figure 1: Areas of Pharmacy Profession. (Source: Pharmacy council of India)

universities or in a university department. Students holding a BPharm degree can earn an MPharm degree in 2 years, of which the second year is devoted to research leading to a dissertation in any pharmaceutical discipline, for instance pharmaceutics, pharmacology, pharmaceutical chemistry, or pharmacognosy. Recently, MPharm programs on industrial pharmacy, quality assurance, and pharmaceutical biotechnology have been introduced. To train the graduate pharmacist to provide clinical-oriented services, the MPharm program in pharmacy practice was introduced at Jagadguru Sri Shivaratreeswara (JSS) College of pharmacy at Mysore in 1996 and at Ooty in 1997. There are 6 National Institutes of Pharmaceutical Education and Research (NIPERs) in India offering MS (Pharm), MTech (Pharm), and higher-level degrees. The NIPERs were created with the vision of providing excellence in pharmacy and pharmacy-related education. Students with an MPharm degree in any discipline can work toward a $\mathrm{PhD}$ with an additional minimum 3 years of study and research. The PharmD program constitutes 6 years of full-time study. The PharmD (post-baccalaureate) program is a 3-year program. The PharmD program was introduced in 2008 with the aim of producing pharmacists who had undergone extensive training in practice sites and could provide pharmaceutical care to patients (Kaul, 2009).

\section{Growth of Pharmacy Education}

Prior to mid 1980s, the growth of publicly funded institutions of higher education (including pharmacy institutions) was very slow. Until early 1980s, there were 11 universities and 26 colleges offering pharmacy education at the bachelor's and master's 
levels. Addition, there was at least 1 government school in every Indian state offering the DPharm program. Since the late 1980s, due to rapid industrialization in the pharmaceutical sector, privatization, and economic growth, pharmacy education has been developing faster in India than anywhere in the world. In 2007, there were 854 institutions that admitted more than 52,000 students to the BPharm degree program and 583 institutions that trained more than 34,000 students in the DPharm degree program. Most of the institutions, however, are privately funded colleges or privately funded universities. The private sector, which accounted for about $10 \%$ of the students admitted in the 1980s, now accounts for $91 \%$ of all pharmacy students admitted (Singh, 1994).

While there are a large number of DPharm and BPharm graduates each year, the number of students that has graduated in any state varies widely. A large number of privately funded institutions are located in states like Tamilnadu, Karnataka, Andhra Pradesh, Maharasthra, and Gujrat. In Tamilnadu, around 45 colleges and universities educate approximately 2,960 DPharm and 2590 BPharm graduates per year (within a total state population of about 64 million) (Singh, 1994).

\section{PHARMACY EDUCATION IN BANGLADESH}

In 1964, 1st July Pharmacy Education started its endless journey under the supervision of Professor Emeritus Dr. Abdul Jabbar which roams around him till today (Jamshed, 2007). In 1947, there was no institute for pharmacy education in the newly born Pakistan though there were lots of thoughts to open such an institute. In response to the introduction of Pharmacy profession and its brighter aspects in abroad and development of foreign pharmaceutical companies in Pakistan, Lahore University opened pharmacy department in mid 1948 in West Pakistan (present Pakistan). From the partition of subcontinent the gradual discrimination towards East Pakistan (Bangladesh) also affected the Pharmacy Education, though a good number of students of this part were interested in Pharmacy. But they didn't get the chance. At that period Prof. Dr. Abdul Jabbar strongly felt the necessity of Pharmacy Education when he was adopting higher degree in abroad and tried to admit some students in Lahore
University every year. But only 2 to 4 students got the chance among the 10 to 15 's though they were truly qualified. Those days went on in this way (Jamshed, 2007).

During the late 50's there were few small pharmaceutical companies in East Pakistan (Bangladesh). The demand of medicine market was fulfilled through importing. Moreover, some big companies named Albert David, Glaxo and Baroz Welcome went on production, which needs Pharmacists though there was no scope to fill the demand.

Gradually increasing demand of the Pharmacists and the discrimination faced by the students of East Pakistan initiated the thought to start Pharmacy Education in Dhaka University. And Dr. Abdul Jabbar was the First to initiate the process. During that period renowned Educationist Dr. Mahmud Hussain was the Vice Chancellor of Dhaka University. With his help a scheme of establishing Pharmacy department in Dhaka University was sent to Planning Commission several times. But Planning Commission of Government refused to do so, mentioning the lack of teachers. Though in Lahore University Pharmacy education ran under teachers who were not pharmacists, for more than one decade and a new plan was passed to start Pharmacy in Karachi University. Moreover, from 1950's Biochemistry and Pharmaceutical Chemistry existed as subsidiary subject under Chemistry department in Dhaka University. Thus today it's not difficult to understand the decision was just an expression of discrimination (Jamshed, 2007).

Meanwhile Dr. A.Jabbar got a fellowship in SanFrancisco School of Pharmacy, USA for one year in 1960 and Biochemistry was established as separate department. Dr. Kamaluddin Ahmed was selected as Chairman. Coming back Dr. A. Jabbar with Dr. Kamal started again to set up a platform for pharmacy. Moreover, Dr. Kamal sent three meritorious students named Mr. Abdur Rashid, Mr. shukur Khan and Mr. Shamsul Alam Talukdar for higher studies during 1961-62. Thus the lack of teachers was solved.

Afterwards Dr. A. Jabbar and Dr. Kamal interacted with the University administration to start the Pharmacy education. Prof. Mahmud Hossain as 
Vice Chancellor passed the proposal and sent to Planning Commission. Today we must reminiscence the name of those great persons to whom we are grateful, the Education Minister of East Pakistan Late Mafizuddin Ahmed and Economist Late Dr. M. N. Huda and Dr. K. T. Hossain who shortly joined in planning commission. At last with their reference Planning Commission was bound to approve the proposal in late 1962 (Chowdhory, 2007).

After the approval by Planning Commission raised the questions of syllabus, teachers, associates, chairman, place etc. The syllabus was taken as the syllabus of London School of Pharmacy, which was worldwide, recognized for Pharmacy at that period. It was decided to take class in the classrooms of Biochemistry Department, which is situated in the Carzon Hall. Though Dr. Abdul Jabbar was the only teacher who did fellowship in pharmacy at that period, due to some political movement in 1962, Dr. Kamaluddin Ahmed was selected as chairman of both Biochemistry and Pharmacy. Few days later Dr. Abdul Jabbar was selected as First chairman of Pharmacy Department (Chowdhory, 2007).

Though Pharmacy department was started as 3 years professional B.Pharm degree in 1964, it was converted into 3 years B.Pharm (Hons) degree in 1965 due to protest from the students. In 1967 the first B.Pharm batch passed out.

\section{Pharmacy Schools in Bangladesh}

There are 6 public universities and 22 private universities in Bangladesh with Pharmacy Department The Pharmacy Schools in Bangladesh offers various undergraduate and post-graduate courses in Pharmacy to the students who are willing to take pharmacy as their field of study and want to make a successful career on it. Public universities follow yearly system of four years degree course and one year masters. Private universities follow semester system. Course curriculum generally follows DU syllabus. There is a good amount of interest in Pharmacy studies in Bangladesh. Every year, the Pharmacy Schools in Bangladesh attract a good number of students. In the field of Pharmacy, there is ample opportunity for the students make a successful career in Bangladesh (Chowdhory, 2007).
There are a number of Pharmacy Schools in Bangladesh where the students can get enrolled to pursue various courses in Pharmacy. The names of the Pharmacy Schools in Bangladesh could be said as below:

- University of Dhaka - Faculty of Pharmacy

- Khulna University - Pharmacy Discipline

- University of Rajshahi - Department of Pharmacy

- Jahangirnagar University - Department of Pharmacy

\section{Future of Pharmacy Profession in Bangladesh}

For proper development of the country, our prime need is to ensure healthier and educated manpower. A healthier nation is only possible when everyone should have equal access to health care providers, and proper and rational management of drugs and diseases are ensured. A health care team consisting of physician, pharmacist and nurse can only ensure the drugs and diseases management in judicious and rational way (Ahmed, 2008). Pharmacists have the expertise in drug management and dispensing, monitoring of drug-drug interactions, and clinical research. Moreover, reschedule of dosage regimen to individual patient can only ensure the rational prescribing and use of medicines and this is the prime task of clinical pharmacists.

The practice of pharmacy will become ever more important in the developed and developing country with more potent drugs coming to the market. Pharmaceutical care will be an important component of health care as the awareness of adverse drug reaction, pharmacogenomics and pharmacoeconoics and socioeconomic factors associated with health and diseases are being recognized. Rising longevity will increase dependence on medicines and hereby on the pharmacists. Regulatory affairs and Drug Administration will play more important role in the country. Countries own drug consumption will see a phenomenal increase with the rise in purchasing power of the people. So the pharmaceutical industries will witness a rapid increase in growth resulting in more demand of manpower in the industries. Global concern for better health care at an affordable price involving all types health personnel, doctors, pharmacists, nurses, social scientists, economists will favour the developing countries having knowledge and skill in the areas mentioned above (Ahmed, 2008). 


\section{PHARMACY EDUCATION IN PAKISTAN}

In 1948 University of Punjab was the first institution to develop a pharmacy department in Pakistan immediately after the independence. The first pharmacy degree program started in Pakistan was a three-year bachelor program, which was extended to four years in 1978-1979. By the year 2000 not more than ten public universities were offering Bachelor of Pharmacy (B.Pharm) program and the annual number of graduates were not that sufficient to fulfill the need of pharmaceutical industry.

But latter due to the establishment of the private universities or in other words the commercialization of education the annual number of the pharmacist becomes doubled by the year 2003. Moreover, during this time massive funds were granted to Higher education commission of Pakistan in order to establish faculties and to revise the curriculum according to the international standards. In the vague to fulfill the international standards, the four years B.Pharm Program was upgraded to five years Doctor of Pharmacy (Pharm-D) program. The main focus of this program was to incorporate the role of pharmacist in patient care which hardly to see in any public and private hospital (Mohamed, 2009).

\section{Pharmacy Schools in Pakistan}

In the last 5 years, there has been a rise in the number of pharmacy institutions in the country; currently about 17 universities are imparting pharmacy education. Though, the number of institutions has almost doubled, the change is more quantitative (Hadzovic, 1997).

In Pakistan, pharmacy education was already there when it came into existence but it has been neglected and has failed to contribute significantly to national healthcare. In the last 5 years, there has been a rise in the number of pharmacy institutions in the country; currently about 17 universities are imparting pharmacy education. Though, the number of institutions has almost doubled, the change is more quantitative than qualitative. In 2004, the Higher Education Commission (HEC) of Pakistan revised the pharmacy syllabus and changed the 4 year Bachelor of pharmacy (B.Pharm) degree to a 5 year Doctor of Pharmacy (Pharm. D.). The Syllabus was revised but it still shows insuffi- ciencies and shortcomings and does not meet international standards (Hadzovic, 1997).

List of some pharmacy colleges:

- Gomal University-Faculty of Pharmacy

- Islamia University-Faculty of Pharmacy

- Karachi University-Faculty of Pharmacy

- Peshawar University-Department of Pharmacy

- Sindh University-Faculty of Pharmacy

- University of Punjab-Faculty of Pharmacy

- Baluchistan University- Department of Pharmacy

\section{Challenge to Pharmacy Education in Pakistan}

It was seen that the main focus of the pharmacy education sector was to produce the graduate to fulfill the needs of pharmaceutical industry only. During earlier time merely one or two pharmacist were found in few private hospital in Pakistan, particularly speaking in term of government hospital the picture was even miserable, firstly there was no post for the pharmacist in the hospital and if there was any that was occupied by a medical doctor as medical store in-charge (Ghaffer, 1992). However, in 2002 a shift towards the Pharm-D program was noticed and it was made necessary to upgrade Bachelor of Pharmacy (B.Pharm) to PharmD. With the up-gradation of B.Pharm program to Pharm-D, the advertising trends by the pharmaceutical industry in Pakistan are changed. The minimum qualification requirement for the post of production officer, quality control officers and marketing officer/ medical sale representative by the most of the pharmaceutical industries is changed from B.Pharm to Pharm-D (Ghaffer et al., 1992).

In the future those applying to the pharmaceutical industry for these jobs with B.Pharm degree will get a NO, because the human resource departments will give preference to Pharm-Ds. It is possible that majority of the national pharmaceuticals firms will follow the same trend which will raise challenges for the B.Pharms to work in the industry (Ghaffer et al., 1992).

In other words one can assume that Pharm-D professional will be incorporated to play their role in pharmaceutical product manufacturing, marketing or distribution instead of the patient oriented care. In spite of the fact this issue is still in the 
neglected issues in the pharmacy education. It is strongly needed to take some immediate initiative to ensure the job security of the B.Pharm Graduates that were especially prepared for the pharmaceutical sector and they have the relevant experience as well. To compensate this problem condensed / crash Pharm-D course is offered to the B.Pharm Graduates and they will be awarded with the certificate that will prove their educational equivalence to Pharm-D. But again this certificate will be merely a tag for them because the condensed course has focus on the clinical aspects that are oriented to the direct patient care not to the pharmaceutical industry (Imran, 2009).

In addition a Pathway Program can be adopted which focus solely on pharmaceutical technology instead of clinical aspects of pharmacy practice. The first three years will focus on the basic medical science as they are in the current Pharm-D curriculum and after three years students are given an option to choose their favorite i.e. clinical pharmacy or pharmaceutical technology. In other words a five year professional programme, i.e. Doctor of Pharmaceutical technology will be an ideal approach to fulfill the need of the pharmaceutical industry in Pakistan. Pharmacy education and practice in Pakistan needs drastic improvement in the curriculum, infrastructure, administration, regulations and accreditation criteria for movement to Pharm. D., a patient oriented profession. Some measurements can enhance pharmacist's role in health care provisions in Pakistan and can enable Pakistani pharmacists to compete with the international pharmacist community, so that their degrees will earn better respect even in developed countries (Hamarneh, 1962).

\section{SUMMARY}

These are times of enormous change in healthcare and the pharmacy profession and pharmaceutical education must prepare students to enter into the practice of pharmacy, in whatever areas are appropriate to the environment. Pharmacy education in India, Pakistan and Bangladesh both at the B.Pharm and M.Pharm levels, is taught as an industry- and product-oriented profession with a focus on the basic sciences. The pharmacists generally seek avenues other than pharmacy practice. These pharmacists prefer placements in production, regulatory affairs, management and/or quality assurance, and marketing with the pharmaceutical industry. In order to demonstrate the requirements for pharmacists it is necessary to undertake a pharmacy workforce study, to review pharmacy education programs, and to compare them with the roles that have been accepted internationally. Then, to design and develop pharmacy degree programs-perhaps one program exclusively for industry and another for practice.

\section{REFERENCES}

Ahmed, S.I. (2008) The Controversy of Pharm. D. Degree (letter), Am J Pharm Edu. 72(3), Article 71.

Chowdhury, A.K.A. (2007) Pharmacy education in Bangladesh: past, present and future. BAPA Journal, Aug, 10-14.

Ghaffar, A., Kazi, B.M., Salman, M. (1992) An Overview of the Health Care System in Pakistan.

Hadzovic, S. (1997) Pharmacy and great contribution of ArabIslamic science to its development, Med Arh, 51(1-2):47-50.

Hamarneh, S. (1962) The rise of professional pharmacy in Islam. Med Hist, 3:59-66.

Hepler, C.D., Strand, L.M. (1990) Opportunities and responsibilities in pharmaceutical care. Am J Hosp Pharm, 47:533-543.

Imran,M.(2009) Journal of Public Health Medicine, 22:38-42.

Jamshed, S. (2007) The Pharm. D. degree in developing countries. Am J Pharm Edu, 71(6), Article 125.

Jesson, J.,Bissell, P.(2006) Public health and pharmacy: A critical review. Critical Public Health, 16:159-169.

Kaul, R. (2009) History of modern pharmacy in India: a review of the work of Professor Harkishan Sing.Pharm Hist, 54(1):34-42.

Lal, L.S., Rao, P.G. (2005) Clinical pharmacy education in India. Am J Health-Syst Pharm. 62:1510-1511.

Miglani, B.D. (2008) Sixth pay commission report-fatal blow for practicing pharmacists, Pharma Review, 7:69-70.

Mohamed,A.H. (2009) The role of pharmacists in developing countries: the current scenario in Pakistan. Hum Resour Health, 7:1478-1489.

Pharmacy council of India, http://www.pci.nic.in accessed on November, 2009

Singh, H. (2009) Pharmaceutical education and pharmacy practice: A historical perspective. Pharma Times, 41(2):16-18.

Singh, H. (1994) History of Pharmacy in India and Related Aspects.Pharmaceutical Education, Vallabh Prakashan.2 (1): 78-81. 